\title{
The Complex Nature of Text Reading Difficulties: The Case of Bilingual Children
}

\author{
Raphiq Ibrahim ${ }^{1,2 *}$, Suha Shibel2, Rachel Hertz-Lazarowitz ${ }^{3}$ \\ ${ }^{1}$ The Edmond J. Safra Brain Research Center for the Study of Learning Disabilities, University of Haifa, Haifa, Israel \\ ${ }^{2}$ Learning Disabilities Department, University of Haifa, Haifa, Israel \\ ${ }^{3}$ Learning, Instruction and Teacher Education Department, University of Haifa, Haifa, Israel \\ Email: raphiq@psy.haifa.ac.il
}

Received 24 August 2014; revised 21 September 2014; accepted 16 October 2014

Copyright (C) 2014 by authors and Scientific Research Publishing Inc.

This work is licensed under the Creative Commons Attribution International License (CC BY).

http://creativecommons.org/licenses/by/4.0/

(c) (i) Open Access

\section{Abstract}

The present research examined the effect of nature of orthography on the development of reading acquisition among children acquiring Arabic and Hebrew. Speed and accuracy measures were examined in reading texts in Arabic and in Hebrew. It was found that Arabic speakers showed an almost equal control in reading both languages. Furthermore, it was found that the speed of reading texts in Arabic among Arabic speakers was 3 times slower than reading Hebrew texts among Hebrew readers. These findings confirm that there is difficulty in identifying and decoding visual stimuli in Arabic. Furthermore, findings of the present research paper emphasizes that reading in Hebrew is faster and more precise than reading in Arabic, beyond mother tongue groups (Arab and Hebrew speakers). In addition, Hebrew readers showed a significant difference in reading in favor of reading in their mother tongue (both in accuracy and speed). In conclusion, findings of the present research suggest that there is an objective difficulty in acquiring reading of the Arabic language, and there is need for systematic intervention among those who face difficulties in the learning process.

\section{Keywords}

Bilingual, Orthography, Reading, Arabic, Hebrew, Diglossia

\section{Introduction}

Reading includes the ability to decode morphemes into meaningful words aiming at understanding the whole text. This includes skills based on phonological processing such as phonemic synthesis and analysis, as well as

${ }^{*}$ Corresponding author. 
skills such as working memory in the process of second-language reading acquisition (Sparks \& Ganschow, 1993; Service, 1992). Proof for the existence of skills transfer between languages was obtained in a long-term study by Dufva \& Voeten (1999), this study supported the importance of phonological working memory in the process of second-language reading acquisition. Other researchers showed that control of reading and writing skills in the first language facilitates the acquisition of a second language, as there is transfer of acquired reading skills from one language to the other, such as phonological awareness, perception of print, orthographic knowledge and general knowledge (Pang \& Kamil, 2004).

The main theory accepted in the field of second language and bi-lingual learning establishes a connection between academic success and ability of acquiring a second language to a mother tongue level (Cummings, 1979, 1981). In this context, Cummins (1991) proposed the interdependence hypothesis, according to which children who developed literacy in one language will advance faster in the second language through the transfer of skills (Cummins, 2000). These positive effects will occur only if there is sufficient exposure to the second language and motivation to learn it, in addition to literacy skills in the first language.

A study dealing with second-language learning speed showed that exposure to reading materialor to literacy established in the mother tongue is a major success measure in second-language acquisition (Barkon \& Avinor, 1995). Furthermore, this study showed that the first language affects the learning of the second language; that is, knowledge of the mother tongue in general and literacy in particular, affects successful learning of the second language (Brown \& Haynes, 1985; Koda, 1990; Akamatsu, 2003). In this context, phonological awareness of the first language was found to predict word identification and decoding skills in the second language (Cisero \& Royer, 1995). Another research has found a relationship between the acquisition of phonological decoding in the mother tongue and reading acquisition in the second language (Ibrahim, Eviatar, \& Aharon-Peretz, 2007). Phonological awareness was found to be a significant predicting factor of reading achievements in both languages, regardless of the nature or type of the mother tongue (Muter \& Diethelm, 2001; Quiroga, Lemos-Britton, Mostafapour, Abbott, \& Berninger, 2002).

Abu-Rabia and Siegel (2002) examined, for example, skills in three different orthographies: Arabic, Hebrew and English, among Arabic mother tongue speakers. They found that many skills in the first language, among them reading, phonological and orthographic processing, working memory and spelling were found in high correlation with spelling in English (Abu-Rabia \& Siegel, 2002). Sparks \& Ganschow (1991) proposed the Linguistic Coding Difference Hypothesis-LCDH, according to which, success in learning a second language is based on phonological, orthographic and syntax skills in the mother tongue (Sparks \& Ganschow, 1991). Furthermore, they showed that students experiencing difficulties in second-language acquisition were found to have linguistic weaknesses in their mother tongue (Ganschow, Sparks, \& Schneider, 1995).

The present research examines two languages-Arabic and Hebrew, posing certain unique challenges in the orthography aspect. Despite the difference between the two orthographies in their writing systems, when words are vowelized, they are considered "shallow" languages; i.e. there is a one-to-one relationship between the grapheme and the phoneme, and on the contrary, they are considered "deep" languages when words are not vowelized (Abu-Rabia, Share, \& Mansour, 2003).

\subsection{Reading in Arabic and Hebrew}

Reading Arabic and Hebrew orthographies with vowel diacritics might be expected to facilitate early decoding by reducing phonological ambiguity (Shimron \& Navon, 1981). Shimron and Navon examined the role of Hebrew vowels in reading speed. They found that fourth grade named isolated pointed words faster than unpointed words. Further, vowels also facilitate adult readers speed, and even the homophonic substitutions did not slow there naming speed. The researchers suggest that vowels diacritics assist isolated words pronunciation for both skilled and less skilled readers and that pointing may be integral to the orthographic representations of children but not adults.

Frost \& Bentin (1992) suggest that vowels in Hebrew are not critical for locating a specific lexical entry, and the consonant structure is sufficient for specifying a target word. These authors concluded that despite the ambiguity of the unvoweled Hebrew, skilled readers do not need the vowel diacritics for reading. In this line of researches, Koriat (1985) found that the unvoweled words were words that had only one meaningful pronunciation in their unvoweled form. The results showed that the lexical decision latencies for voweled and unvoweled words were not significantly different. Relying in Koriat's (1985) data, Koriat concluded that the presence of 
vowels marks did not influence visual word recognition except in low-frequency words. It is important to note that all the previous studies in Hebrew tested single word reaction time and not reading accuracy.

However, it is essential to mention here, that when native Hebrew subjects required to read isolated voweled and unvoweled words, the finding indicate that voweled words are read aloud faster than unvoweled words, despite the fact that decoding of voweled words requires processing more information. Further, when words were presented in context, the contribution of the vowel signs was extremely reduced (Navon \& Shimron, 1985). This may be evidence for top-down compensation for the lack of vowel signs (Shimron, 1999).

A similar issue in Arabic, also a Semitic language, has been addressed. Abu-Rabia \& Siegel (1995) investigated the effect of vowels among eighth graders poor and skilled readers, they found that vowelization improved the reading accuracy of both skilled and poor readers' especially words in context. Shimron (1999) suggested that there may be another source of information that contributes to reading of unvoweled Hebrew beyond phonological information.

It is well known that metalinguistic ability, specifically, phonological awareness, is positively related to the acquisition of reading (Share, Jorm, Maclean, \& Matthhews, 1984). In previous study, we have shown that children exposed to both forms of Arabic function as bilinguals, as they show higher levels of phonological awareness than age matched monolingual Hebrew speakers (Eviatar \& Ibrahim, 2001). This would predict that they should show an advantage in reading acquisition. However, the opposite finding has been reported: reading acquisition in Arabic is slower than in Hebrew. In order to examine this question, we measured the relationship between phonological abilities and various reading measures in first grade in children learning to read Hebrew or Arabic (Ibrahim et al., 2007). First graders were given a series of tests of phonological awareness and a vocabulary test, and given grade level texts to read. The correlations between the metalinguistic measures and reading showed that for the Arabic speaking children, there is a weaker relationship between phonological abilities and reading in Arabic than in Hebrew. It can also be seen that the children who are reading Arabic read more slowly and make more errors than the children who read Hebrew. Thus, although the Arab children evince higher levels of phonological abilities than monolingual Hebrew speakers, this phonological advantage does not translate into an advantage in reading acquisition. What could be the reason for this? MSA has an alphabetic orthography, like English and Hebrew, and in both these languages, phonological awareness is a very good predictor of success in reading acquisition. One possible answer to this is that this is an effect of the diglossia-the two groups who were reading Hebrew were fluent in Hebrew, while Arab children are learning to read a language which is different from their native language (Ibrahim \& Aharon-Peretz, 2005; Ibrahim, 2009). However, it has been shown that skilled adult readers of Arabic also read more slowly than skilled adult readers of other languages (Azzam, 1993). Therefore, diglossia cannot be the only reason for this pattern. Other group of researchers' results sees both lexical and perceptual factors that influence the process of visual word recognition in Arabic (Roman \& Pavard, 1987; Ibrahim et al., 2002).

\subsection{Linguistic Reality in Israel}

The education system in Israel largely preserves the existing disconnection between Jews and Arabs: most schools are uni-national, and although Arabic is an official language in Israel, Jewish pupils are exposed only to the Arabic language to a limited extent specifically and to Arabic culture in general compared to Arab pupils, who study Hebrew language, literature and culture to a quite large extent (Amara \& Mar'i, 2002; El-Hajj, 2003). Bi-lingual education in Israel constitutes an alternative to the current reality in a number of aspects: social, learning, and cultural. The development of models for bi-lingual schools is one of the challenging and interesting ways to challenge this reality (Hertz-Lazarowitz, Azaiza, Peretz, Zelniker, \& Sharabany, 2007).

Three schools were established by the Hand in Hand Association for Bi-Lingual Education in Israel in the three areas of Jerusalem, Misgav-Sakhnin and WadiAra. Each school is attended by several hundreds of pupils, approximately half Jewish and half Arab. These bi-lingual schools emphasize symmetry between the Hebrew and Arabic languages in all aspects of teaching. General conversation in class is conducted in both languages, with no translation, according to the bi-lingual model of Amara and colleagues, adopted by the school (Amara et al., 2007).

\subsection{The Current Study}

In the present study we compare Arabic and Hebrew native speakers in reading texts in both the Arabic and Hebrew languages, in measures of reading accuracy and speed. In addition, a comparison was carried out for each 
subject in reading tasks of the two languages.

As the performance in the second language was compared between the two groups of the different mother tongues (Arabic and Hebrew), we examined the transfer of linguistic abilities in the mother tongue to a second language depend on the type and structure of the language.

We hypothesized that performance in reading texts (reading accuracy and speed) in Hebrew and Arabic (respectively) will reflect the different nature of the transfer from the first to the second language. We expect that Hebrew mother tongue children will experience more difficulty in learning the Arabic language as a second language compared to the Hebrew as a second language for Arabic mother tongue speakers, due to the complexity of the Arabic language.

Every result that would point at relative difficulty in acquiring the Arabic language would strengthen the conclusions of previous studies on the existence of additional complexity of the Arabic orthography over other languages (Taouk \& Coltheart, 2004; Ibrahim, Eviatar, \& Aharon-Peretz, 2002; Eviatar, Ibrahim, \& Ganayim, 2004; Abu-Rabia, 1997; Azzam, 1993).

\section{Method}

\subsection{Participants}

The study included 49 subjects with a 9.3 average age (S.D. six months) and from two age groups: 32 from the third grade and 17 from the fourth grade. The study was carried out in two bi-lingual schools in Israel: "The Galilee" and "Bridge on the Wadi". All subjects from the two groups were matched on age, and children with physical disabilities (sight or hearing) were excluded because such impairment as variable would have compromised the results. Mother tongue teachers, who in this case were also the home room teachers, chose the pupils with the best control of reading in both Arabic and Hebrew languages and who did not suffer from any learning disabilities.

\subsection{Materials}

\section{Texts}

In order to answer the research question, three vowelized reading texts were prepared and divided into three levels: easy, medium and difficult, in both Arabic and Hebrew. Initially a number of texts in Arabic and Hebrew were taken from textbooks and presented by the staff of first and second language teachers in both schools participating in the study. They were then rate on a five Likert scale from very easy to very difficult (very easy, easy, medium, difficult, very difficult). The decision to rate on five Likert scale from very easy to very difficult rather than on a three Likert scale was to allow more options and variability in selection.

Three types of texts were chosen in Arabic and Hebrew: easy level (50 words), medium level (92 words), and difficult level (146 words). The texts in the two languages were matched in their number of words as well as in the themes of each sentence.

A reliability measure test according to alpha Kronbach was carried out on the texts (see Table 1). Table 1 shows that beyond the two language groups, reliability scores and reading speed in the different tests range from 0.86 and 0.98 .

\subsection{Procedure}

The study was carried out in a quiet room at the school and in a pleasant and comfortable setting on an individu-

Table 1. Means of Accuracy (\%) and text reading speed (in seconds), Standard Deviation and Reliability of the various measures designed for texts $(\mathrm{N}=49)$.

\begin{tabular}{ccccc} 
Test & Means & S.D. & Reliability & Number of items \\
\hline Accuracy in reading text in Arabic (\%) & 84.11 & 23.83 & 0.98 & 2 \\
Speed in reading text in Arabic (sec) & 67.28 & 61.88 & 0.97 & 2 \\
Accuracy in reading text in Hebrew (\%) & 96.4 & 4.02 & 0.86 & 2 \\
Speed in reading text in Hebrew (sec) & 33.14 & 22.08 & 0.98 & 2 \\
\hline
\end{tabular}


al basis with every subject. The session with each subject began with a short acquaintance, creating a pleasant atmosphere, and providing a brief explanation about the essence of the meeting (Schiefelbusch \& Rice, 1989). It was also meant to remove any fears or hesitations. After the subject approved that the task may begin, it was explained to him that he has to read the three texts (easy, medium and difficult) in both Arabic and Hebrew as fast and as accurate as possible. It was explained and emphasized to all subjects that there would not be any questions at the end of the reading test. The order of presenting the texts was alternated among the subjects in order to cancel the effect of the order.

\section{Results}

Average reading times and accuracy rates in all the reading tasks in both languages constituted the dependent variables. The results for each of the hypotheses presented in the introduction are presented separately, while the main research question was: is the Arabic language more difficult to process and acquire than the Hebrew language?

Reading times and accuracy rates were analyzed; mother tongue (Hebrew speakers and Arabic speakers) and test language (Arabic and Hebrew) were independent variables.

In order to examine differences in text reading speed according to nationality and test language, a two-way variance analysis of text reading speed was carried out according to nationality and test language, with repeated measures for test language. Significant differences were found according to nationality $(\mathrm{F}(1,47)=31.97, p<$ $\left.0.001, \eta_{p}^{2}=0.41\right)$. Further, Arabic speakers were found to be faster $(\mathrm{M}=35.11, \mathrm{SD}=14.48)$ than Hebrew speakers $(\mathrm{M}=70.34, \mathrm{SD}=28.49)$. Differences were also found according to test language $(\mathrm{F}(1,47)=60.08, p<$ $0.001, \eta_{p}^{2}=0.56$ ). In addition, text reading was faster beyond the groups (nationality) in reading in Hebrew ( $\mathrm{M}=$ 31.08, $\mathrm{SD}=22.08)$ than in Arabic $(\mathrm{M}=74.37, \mathrm{SD}=61.88)$. Finally, interaction was found according to nationality and test language $\left(\mathrm{F}(1,47)=131.51, p<0.001, \eta_{p}^{2}=0.74\right)$ (see Figure 1 ).

A post hoc test reveals that for Arabic mother tongue subjects, no differences were found in reading speed between reading a text in Arabic $(M=24.73, S D=8.38)$ and reading a text in Hebrew $(M=45.49, S D=21.88)$, compared to Hebrew mother tongue subjects. For the latter, reading speed in reading Hebrew a text was found to be faster $(M=16.68, S D=5.10)$ than reading speed in reading a text in Arabic $(M=124, S D=56.41)$. Further, it was found that in reading texts in Arabic the reading speed of Arabic speaker as mother tongue was faster than the reading speed of Hebrew speakers as mother tongue, while in reading texts in Hebrew the reading speed of Hebrew speakers was faster that the reading speed of Arabic speakers.

Additional findings show that Hebrew speakers get higher scores on reading words in their mother tongue than Arabic speakers $\left(\mathrm{F}(1,47)=11.98, p<0.001, \eta_{p}^{2}=0.20\right)$, and differences were found in reading speed in the mother tongue. According to mother tongue, it was found that the reading speed of Hebrew speakers was faster than the reading speed of Arabic speakers $\left(\mathrm{F}(1,47)=19.45, p<0.001, \eta_{p}^{2}=0.29\right)$.

In order to examine differences in accuracy of reading texts in the mother tongue according to nationality, a two-way variance analysis of speed reading texts in mother tongue was carried out according to nationality and type of text (easy, medium, difficult) and significant differences were found $\left(\mathrm{F}(1,47)=16.41, p<0.001, \quad \eta_{p}^{2}=\right.$ 0.26): Hebrew speakers were faster $(M=16.53, S D=5.07)$ than Arabic speakers $(M=24.77, S D=8.20)$.

Furthermore, differences were found according to type of text $\left(\mathrm{F}(2,94)=11.04, p<0.001, \eta_{p}^{2}=0.19\right)$ : in

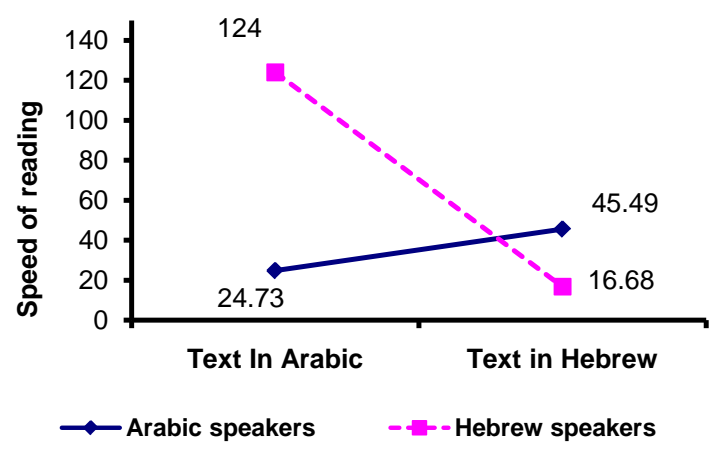

Figure 1. Interaction of speed in reading (in seconds) according to nationality and language test. 
reading a medium text the speed was slower $(M=22.53, S D=9.41)$ than when reading an easy text $(M=20.03$, $\mathrm{SD}=7.31)$ and a difficult text $(\mathrm{M}=21.15, \mathrm{SD}=8.25)$. No interaction was found according to nationality and type of text $\left(\mathrm{F}(2,94)=0.83, p>0.05, \eta_{p}^{2}=0.004\right)$.

To examine differences in text reading accuracy in mother tongue according to nationality and type of text, a two-way variance analysis of reading texts in mother tongue (Arabic, Hebrew) scores was carried out according to nationality (Arabic mother tongue speakers and Hebrew mother tongue speakers) and type of text (easy, medium, difficult), revealing significant differences according to nationality $\left(\mathrm{F}(1,47)=11.56, p<0.001, \quad \eta_{p}^{2}=\right.$ $0.20)$; i.e. Hebrew speakers are more successful $(\mathrm{M}=99.05, \mathrm{SD}=0.84)$ in reading their mother tongue than Arabic speakers $(\mathrm{M}=96.91, \mathrm{SD}=2.78)$ beyond the task difficulty level. Further, differences were found according to type of text (easy, medium, difficult) $\left(\mathrm{F}(2,94)=13.94, p<0.001, \eta_{p}^{2}=0.23\right)$, and interaction was found according to nationality and type of text $\left(\mathrm{F}(2,94)=17.74, p<0.001, \eta_{p}^{2} \stackrel{p}{=} 0.27\right)$ (see Figure 2 ).

Figure 2 and the results of Bonferroni test reveal that for an easy text (each group in its mother tongue), no differences were found in accuracy between speakers of Arabic $(M=98.57, \mathrm{SD}=2.55)$ and speakers of Hebrew $(\mathrm{M}=99.19, \mathrm{SD}=1.28)$. For medium text (each group in its mother tongue), Hebrew speakers were more successful $(M=98.55, S D=1.47)$ than Arabic speakers $(M=96.89$, $S D=3.56)$. Finally, for a difficult text, Hebrew speakers were more successful $(M=99.41, S D=0.79)$ than Arabic speakers $(M=95.28, S D=3.38)$. To conclude, it can be seen that, the more words there are in a text in Arabic and the more complex the text, both in terms of word characteristics as well as content-wise, the gap in reading accuracy between the two groups increases in favor of Hebrew mother tongue speakers.

In order to examine differences in accuracy of reading texts according to nationality and test language, a two-way variance analysis of text reading scores according to nationality and test language with repeated measures for test language was conducted. Significant differences were found according to nationality $(F(1,47)=$ 26.05, $p<0.001, \eta_{p}^{2}=0.36$ ) for each mother tongue group in its mother tongue. Arabic speakers were more successful $(M=96.14, \mathrm{SD}=00)$ than Hebrew speakers $(\mathrm{M}=82.41, \mathrm{SD}=00)$ beyond the test language, and differences were also found according to test language $\left(\mathrm{F}(1,47)=33.16, p<0.001, \eta_{p}^{2}=0.41\right)$; reading accuracy in the Hebrew language was found higher than reading accuracy in Arabic language. Moreover, the two mother tongue groups (Arabic and Hebrew speakers) were more successful (beyond type of text) in reading in Hebrew $(M=96.71, S D=4.02)$ than in Arabic $(M=81.84, S D=23.83)$. Finally, interaction was found according to nationality and test language $\left(\mathrm{F}(1,47)=48.90, p<0.001, \eta_{p}^{2}=0.51\right)$ (see Figure 3 ).

A post hoc test reveals that for Arabic mother tongue subjects, no differences were found in accuracy between reading texts in Arabic $(M=97.73, S D=2.74)$ and reading texts in Hebrew $(M=94.55, S D=4.44)$, while for Hebrew mother tongue subjects, accuracy in reading texts in Hebrew was higher $(M=98.87, S D=1.00)$ than when reading texts in Arabic $(\mathrm{M}=65.95, \mathrm{SD}=27.32)$. Moreover, difference was found in reading texts in Arabic between Arabic speakers and Hebrew speakers in favour ofthe first, while in reading texts in Hebrew, no differences were found in scores between Arabic speakers and Hebrew speakers.

\section{Discussion}

The aim of the present research is to examine the performance level of Hebrew and Arabic mother tongue speakers in reading tasks in both languages (Hebrew and Arabic) and the degree of the language factor effect on

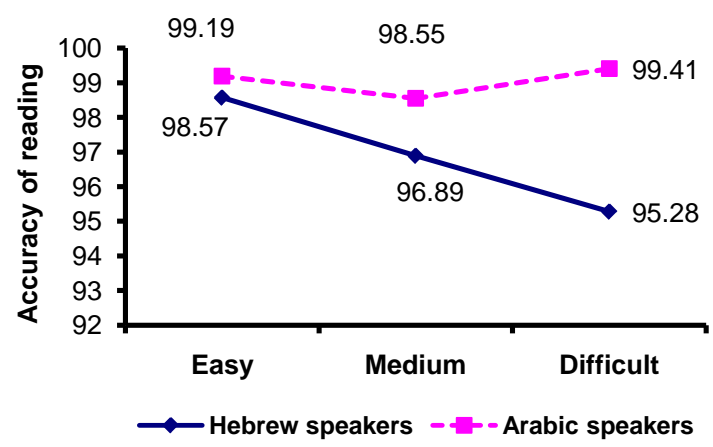

Figure 2. Interaction of percentage of accuracy (\%) in reading according to nationality and type of text. 


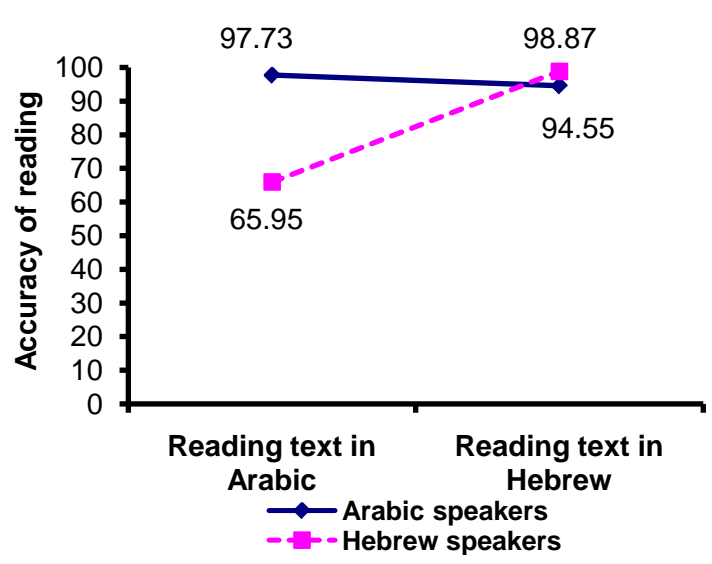

Figure 3. Interaction of accuracy in reading according to nationality and language test.

performance level in reading these languages. Thus, a comparison was conducted in performance level (speed and accuracy) between reading texts in Arabic and Hebrew, while focusing on the unique visual characteristics of the Arabic orthography. In this context, the aim was to find out if the Arabic language is more difficult to process and acquire than the Hebrew language. For this purpose, comparison was conducted in reading acquisition in Hebrew as a second language for Arabic speakers in a bi-lingual setting. The two different mother tongue populations are exposed in the same degree and simultaneously to acquisition of reading and writing in the second language, in the framework of bi-lingual schools in Israel.

The first remarkable finding was that reading in Hebrew was faster and more accurate than reading in Arabic, beyond the mother tongue groups (Arabs, Jews). This finding is especially significant, adding to previous findings dealing with the status of the written Arabic language regarding Arabic speakers on the one hand, and the difficulty due to the visual complexity of the Arabic orthography on the other (Eviatar, Ibrahim, \& Ganayim, 2004; Ibrahim, Eviatar, \& Aharon-Peretz, 2002; Maamouri, 1998; Saiegh-Haddad, 2003). Due to the fact that the visual-orthographic and auditory systems among Arabic readers are sound and they do not suffer from any disabilities, there is no doubt that the slowing down in their reading arises from external factors related to the field characteristics of the language (orthography). This finding is in line with previous findings in reading a text which compared between Arabic language readers and French language readers using letter detection task (Saint-Aubin \& Poirier, 1997) and eye movement technique (Roman \& Pavard, 1987). These previous findings revealed that the gaze duration is longer on words in Arabic than in French. This finding is in line with the findings of other researchers who showed that accuracy in reading in Arabic was significantly lower than that of other languages (Abu-Rabia \& Seigal, 1995; Azzam, 1993).

This finding can be analyzed in a plane analysis between subjects and within subject. In an analysis between subjects Hebrew language speakers were more successful in reading their mother tongue, both in terms of speed as well as accuracy, than Arabic language speakers reading in Arabic. This can be explained according to Maamouri's approach (1998), whereby the Hebrew speaker reads in the language he speaks, while the Arabic speaker does not read the language he speaks, since the literary language is not considered a mother tongue. A similar explanation is provided in a research conducted by Saiegh-Haddad (2003), who proposed that among Arabic mother tongue speakers, the acquisition of reading is affected by diglossia in the Arabic language to a degree of bi-lingualism. The fact that the two languages (spoken and written) are used in different contexts and in different communication function, it preserves and even increases the distance between them. In this context, Ibrahim and Aharon-Peretz (2005) reached the same conclusion: that children Arabic mother tongue speakers function as bi-lingual, being exposed to the two forms of the Arabic language (Ibrahim \& Aharon-Peretz, 2005).

A between subjects analysis revealed that among Hebrew speakers reading speed was three times faster than reading speed of Arabic texts among Arabic speakers, and that reading speed of words in Hebrew among Hebrew readers was 1.6 times faster than the speed of reading words in Arabic among Arabic speakers. Assuming that the time length of learning a language and control level of reading in the mother tongue are similar, it is likely that this delay is created due to the general difficulty of the Arabic language reader in processing texts, and it may be related to the status of the language. 
These findings are in line with the "processing model" of Adams (1990). This model reflects the main processes entailed in the process of reading in a context (Adams, 1990). Adams emphasizes two processes: the process of word identification and the process of meaning production. The process of information extraction in reading occurs simultaneously in a number of processors: phonological, orthographic, semantic, and context. There is synchronization between the four processors in the cognitive system so that the reading process can be performed intact. According to this model, reading definitions will focus both on decoding as well as on meaning production processes.

In the same context, Abu-Rabia and Siegel (1995) found in their research that skilled readers as well as weak readers significantly improved in reading accuracy when they read vowelized and non-vowelized words in context. Additional support was obtained in a continuous study where Abu-Rabia (1997) showed that vowels and context, regardless of writing style, are important variables facilitating reading.

\section{Transfer of Skills from One Language to the Other}

Analysis of the research findings can be carried out according to the interdependence hypothesis of Cummins (1979, 1981). According to this hypothesis, cognitive skills of an academic language are transferred from one language to the other (CALP). In fact, Cummins proposes two assumptions: first, that there is a minimum threshold for linguistic ability in the first language, above which there is avoidance of disadvantage in the cognitive level. That is, a good linguistic ability in the first language acts as a predicting factor of a similar ability in the second language. And indeed, Arabic language speakers read tests in Hebrew in a very similar speed and accuracy to their reading in their mother tongue, and even similar to the reading of Hebrew speakers in their mother tongue. According to this model, it would be expected that Hebrew language speakers would be more successful in reading the Arabic language in a similar way or close to their success in reading in their mother tongue beyond the tests. However, the reading of Hebrew language speakers both in terms of speed and accuracy was found far from their reading ability in their mother tongue and very far from the ability of Arabic language speakers in reading in Hebrew. This finding emphasizes the specific difficulty in Arabic language acquisition due to the unique characteristics of the Arabic orthography, despite it being from the same Semitic source as the Hebrew language and despite the large similarity between the two languages. However, according to Cummins (1981), there is a socio-pedagogic explanation for these findings. According to Cummins, the teaching scope in a certain language is effective for the advancement and fostering of skills and their transfer, given adequate exposure to the second language or sufficient motivation for its learning (Abu-Rabia, 2005).

These two conditions do not occur sufficiently enough in the reality of bi-lingual schools in Israel. There are a number of possible explanations for non-transfer of the abilities of Hebrew language speakers in reading their mother tongue to a second language, Arabic: 1) Children Hebrew mother tongue speakers arrive at the bi-lingual school without a sufficiently strong phonological basis in the Arabic spoken language, as they are not exposed enough to speaking in Arabic language in their environment. In this context, diglossia in the Arabic language, creating a phonological and lexical distance between the two layers of language, the spoken or "amiyya" and the literary or "fusha", substantially influences the low reading achievements of Arabic speaking children (SaieghHaddad, 2003, 2004). Here, it may be assumed that diglossia also affects the progress of children Hebrew mother tongue speakers exposed to "amiyya" in the school environment or to the spoken language in informal settings of discourse and play with their Arabic mother tongue speaking friends, as well as to the literary "fusha" in formal teaching. It may be that diglossia makes it difficult for Arabic mother tongue speakers and apparently also for Hebrew mother tongue speakers in building a quality lexicon and does not allow a faster acquisition of the written language (Perfetti, Yang, \& Schmalhofer, 2008). Additional research is required to examine the effects of diglossia on Hebrew and Arabic speaking children, who live together in a unique setting of a bi-lingual school, mainly in acquiring reading in Arabic. 2) This is an extremely important research in the light of the findings of Ibrahim et al. (2007) regarding differences in reading speed in Arabic and Hebrew among Arabic and Hebrew speakers (Ibrahim, Eviatar, \& Aharon-Peretz, 2007). Ibrahim et al. (2007) examined the utilization of the good phonological awareness among children Arabic mother tongue speakers compared to uni-lingual speakers of other languages (Hebrew speakers) and bi-lingual speakers (Hebrew and Russian speakers) (Eviatar \& Ibrahim, 2001). They found that in reading, Arabic speakers do not utilize this advantage and that their performance in their language (Arabic) is lower (in terms of reading time and accuracy) than other lingual groups. Ibrahim et al. explained that difficulties in processing the Arabic orthography are based on the additional complexity background (visual/orthographic) of the Arabic orthography. 3) It might also be speculated that the greater difficul- 
ties reading Arabic compared to Hebrew may also derive from the fact that Arabic words are more morphemically dense and complex than Hebrew words. For instance, the two words (אכלו אותו) translate into one word in Arabic (أَكَوهُ). In Hebrew, you can also say אכלוהו but this is an archaic form. When reading morphologically complex words the specific representation of vowels is critical for determining the exact word meaning necessary for comprehension. Our assumption is based on the model "word-frequency effect". It proposed that highfrequency words are normally accessed via a visual representation, whereas low frequency words require phonological recoding prior to lexical access (McCusker, Hillinger, \& Bias, 1981). As a result, the addition of vowels was helpful in processing vowelized Arabic text, but was not significant in vowelized Hebrew text.

\section{Conclusion}

The present study compared bilingual Arabic/Hebrew-speaking children in text reading measures. The findings are consistent with previous studies in Hebrew and Arabic and points to a more complex relation between word recognition and reading written text than has been described so far. In that regard, future research will be needed to separate the different functions of this complexity in systematic ways and at different stages of development.

\section{References}

Abu-Rabia, S. (1997). Reading in Arabic Orthography: The Effect of Vowels and Context on Reading Accuracy of Poor and Skilled Native Arabic Readers. Reading and Writing: An Interdisciplinary Journal, 9, 65-78. http://dx.doi.org/10.1023/A:1007962408827

Abu-Rabia, S. (2005). Social Aspects and Reading, Writing, and Working Memory Skills in Arabic, Hebrew, English, and Circassians: The Quadrilingual Case of Circassians. Language, Culture and Curriculum, 18, 27-58. http://dx.doi.org/10.1080/07908310508668732

Abu-Rabia, S., Share, D., \& Mansour, M. (2003). Word Recognition and Basic Cognitive Processes among Reading-Disabled and Normal Readers in Arabic. Reading and Writing: An Interdisciplinary Journal, 16, 423-442. http://dx.doi.org/10.1023/A:1024237415143

Abu-Rabia, S., \& Siegel, L. S. (1995). Different Orthographies, Different Context Effects: The Effects of Arabic Sentence Context in Skilled and Poor Readers. Reading Psychology: An International Quarterly, 16, 1-19. http://dx.doi.org/10.1080/0270271950160101

Abu-Rabia, S., \& Siegel, L. S. (2002). Reading, Syntactic, Orthographic, and Working Memory Skills of Bilingual Arab Canadian Children. Journal of Psycholinguistic Research, 31, 661-678. http://dx.doi.org/10.1023/A:1021221206119

Adams, M. J. (1990). Beginning to Read: Thinking and Learning about Print. Cambridge: MIT Press.

Akamatsu, N. (2003). The Effects of First Language Orthographic Features on Second Language Reading in Text. Language Learning, 53, 207-231. http://dx.doi.org/10.1111/1467-9922.00216

Amara, M., Azaiza, F., Mor-Sommerfeld, A., \& Hertz-Lazarowitz, R. (2007). Hand in Hand Schools: Teaching Programs. Haifa: The Jewish-Arab Center.

Amara, M., \& Mar'i, A. (2002). Language Education Policy: The Arab Minority in Israel. Dordrecht/Boston/London: Kluwer Academic Publishers.

Azzam, R. (1993). The Nature of Arabic Reading and Spelling Errors of Young Children. Reading and Writing, 5, 355-385. http://dx.doi.org/10.1007/BF01043112

Barkon, E., \& Avinor, E. (1995). Academic Difficulties and Early Literacy Deprivation: The Case of Ethiopians in Israel. Language, Culture and Curriculum, 8, 201-209. http://dx.doi.org/10.1080/07908319509525203

Brown, T. L., \& Haynes, M. (1985). Literacy Background and Reading Development in a Second Language. In T. H. Carr (Ed.), The Development of Reading Skills (pp. 19-34). San Francisco, CA: Jossey-Bass.

Cisero, C. A., \& Royer, J. M. (1995). The Development and Cross-Language Transfer of Phonological Awareness. Contemporary Educational Psychology, 20, 275-303.

Cummins, J. (1979). Linguistic Interdependence and the Educational Development of Bilingual Children. Review of Educational Research, 49, 222-251.

Cummins, J. (1981). The Role of Primary Language Development in Promoting Educational Success for Language Minority Students. In California State Department of Education (Ed.), Schooling and Language Minority Students: A Theoretical Framework (pp. 3-49). Los Angeles, CA: Evaluation, Dissemination and Assessment Center, California State University.

Cummins, J. (1991). Interdependence of First- and Second-Language Proficiency in Bilingual Children. In E. Bialystock (Ed.), Language Processing in Bilingual Children (pp. 70-89). Cambridge: Cambridge University Press.

http://dx.doi.org/10.1017/CBO9780511620652.006 
Cummins, J. (2000). Language, Power and Pedagogy: Bilingual Children in the Crossfire. Clevedon: Multilingual Matters.

Dufva, M., \& Voeten, M. J. M. (1999). A Cross-Linguistic and Phonological Memory as Prereguisites for Learning as Foreign Language. Applied Psycholinguistics, 20, 329-348. http://dx.doi.org/10.1017/S014271649900301X

El-Hajj, M. (2003). Education in the Shadow of the Conflict Cultural Hegemony as Opposed to Controlled Multi-Culturalism. In M. El-Hajj, \& A. Ben-Eliezer (Eds.), In the Name of Security (pp. 295-328). Haifa: University of Haifa Press/Pardes Publishing House.

Eviatar, Z., \& Ibrahim, R. (2001). Bilingual Is as Bilingual Does: Metalinguistic Abilities of Arabic-Speaking Children. Applied Psycholinguistics, 21, 451-471. http://dx.doi.org/10.1017/S0142716400004021

Eviatar, Z., Ibrahim, R., \& Ganayim, D. (2004). Orthography and the Hemispheres: Visual and Linguistic Aspects of Letter Processing. Neuropsychology, 18, 174-184. http://dx.doi.org/10.1037/0894-4105.18.1.174

Frost, R., \& Bentin, S. (1992). Reading Consonants and Gussing Vowels: Visual Word Recognition in Hebrew Orthography. Journal of Educational Psycholinguistics, 1, 371-385.

Ganschow, L., Sparks, R., \& Schneider, E. (1995). Learning a Foreign Language: Challenges for Students with Language Learning Difficulties. International Journal of the British Dyslexia Association, 1, 75-95.

Hertz-Lazarowitz, R., Azaiza, F., Peretz, H., Zelniker, T., \& Sharabany, R. (2007). Haifa University: Is It an Umwelt for Dialogue between Religions and Identities? The World Council of Comparative Education Societies (WCCES), Sarajevo, 3-7 September 2007, 137-143.

Ibrahim, R., \& Aharon-Peretz, J. (2005). Is Literary Arabic a Second Language for Native Arab Speakers? Evidence from a Semantic Priming Study. Journal of Psycholinguistic Research, 34, 51-70. http://dx.doi.org/10.1007/s10936-005-3631-8

Ibrahim, R., Eviatar, Z., \& Aharon-Peretz, J. (2002). The Characteristics of the Arabic Orthography Slow Its Cognitive Processing. Neuropsychology, 16, 322-326. http://dx.doi.org/10.1037/0894-4105.16.3.322

Ibrahim, R., Eviatar, Z., \& Aharon Peretz, J. (2007). Metalinguistic Awareness and Reading Performance: A Cross Language Comparison. The Journal of Psycholinguistic Research, 36, 297-317. http://dx.doi.org/10.1007/s10936-006-9046-3

Ibrahim, R. (2009). The Cognitive Basis of Diglossia in Arabic: Evidence from a Repetition Priming Study within and between Languages. Psychology Research and Behavior Management, 2, 93-105.

Koda, K. (1990). The Use of L1 Reading Strategies in L2 Reading: Effects of L1 Orthographic Structures in L2 Phonological Recoding Strategies. Studies in Second Language Acquisition, 12, 393-410.

Maamouri, M. (1998). Language Education and Human Development: Arabic Diglossia and Its Impact on the Quality of Education in the Arab Region. In The Mediterranean Development Forum. Washington, DC: The World Bank.

McCusker, L. X., Hillinger, M. L., \& Bias, R. G. (1981). Phonological Recoding and Reading. Psychological Bulletin, 89, 217-245. http://dx.doi.org/10.1037/0033-2909.89.2.217

Muter, V., \& Diethelm, K. (2001). The Contribution of Phonological Skills and Letter Knowledge to Early Reading Development in a Multilingual Population. Language Learning, 51, 187-219. http://dx.doi.org/10.1111/1467-9922.00153

Navon, D., \& Shimron, J. (1985). Does Word Naming Involve Grapheme-to-Phoneme Translation? Evidence from Hebrew. Journal of Verbal Learning and Verbal Behavior, 20, 97-109. http://dx.doi.org/10.1016/S0022-5371(81)90334-0

Pang, E. S., \& Kamil, M. L. (2004). Second Language Issues in Early Literacy and Instruction. Stanford University, No. 1.

Perfetti, C., Yang, C.-L., \& Schmalhofer, F. (2008). Comprehension Skill and Word-to-Text Integration Process. Applied Cognitive Psychology, 22, 303-318. http://dx.doi.org/10.1002/acp.1419

Quiroga, T., Lemos-Britton, Z., Mostafapour, E., Abbott, R. D., \& Berninger, V. W. (2002). Phonological Awareness and Beginning Reading in Spanish-Speaking ESL First Graders: Research into Practice. Journal of School Psychology, 40, 85-111. http://dx.doi.org/10.1016/S0022-4405(01)00095-4

Roman, G., \& Pavard, B. (1987). A Comparative Study: How We Read Arabic and French. In J. K. O’Regan, \& A. LevySchoen (Eds.), Eye Movements from Physiology to Cognition (pp. 431-440). Amsterdam: North Holland Elsevier.

Saiegh-Haddad, E. (2003). Linguistic Distance and Initial Reading Acquisition: The Case of Arabic Diglossia. Applied Psycholinguistics, 24, 431-451. http://dx.doi.org/10.1017/S0142716403000225

Saint-Aubin, J., \& Poirier, M. (1997). The Influence of Word Function in the Missing-Letter Effect: Further Evidence from French. Memory \& Cognition, 25, 666-676. http://dx.doi.org/10.3758/BF03211308

Schiefelbusch, R. L., \& Rice, M. L. (1989). The Teachability of Language. New York: Paul H. Brooks Publishing Co.

Share, D. L., Jorm, A. F., Maclean, F., \& Matthews, R. (1984). Sources of Individual Differences in Reading Acquisition. Journal of Educational Psychology, 76, 1309-1324. http://dx.doi.org/10.1037/0022-0663.76.6.1309

Shimron, J. (1999). The Role of Vowel Signs in Hebrew: Beyond Word Recognition. Reading and Writing: An Interdisciplinary Journal, 11, 301-319. http://dx.doi.org/10.1023/A:1008045316692

Shimron, J., \& Navon, D. (1981). The Distribution of Information within Letters. Perception \& Psychophysics, 30, $483-491$. 
http://dx.doi.org/10.3758/BF03204845

Sparks, R., \& Ganschow, L. (1991). Foreign Language Learning Difficulties: Affective or Native Language Aptitude Differences? Modern Language Journal, 75, 3-16. http://dx.doi.org/10.1111/j.1540-4781.1991.tb01076.x

Sparks, R. L., \& Ganshow, L. (1993). Searching for the Cognitive Locus of Foreign Language Learning Difficulties: Linking First and Second Language Learning. The Modern Language Journal, 77, $289-302$. http://dx.doi.org/10.1111/j.1540-4781.1993.tb01974.x

Taouk, M., \& Coltheart, M. (2004). The Cognitive Processes Involved in Learning to Read in Arabic. Reading and Writing: An Interdisciplinary Journal, 17, 27-57. http://dx.doi.org/10.1023/B:READ.0000013831.91795.ec 
Scientific Research Publishing (SCIRP) is one of the largest Open Access journal publishers. It is currently publishing more than 200 open access, online, peer-reviewed journals covering a wide range of academic disciplines. SCIRP serves the worldwide academic communities and contributes to the progress and application of science with its publication.

Other selected journals from SCIRP are listed as below. Submit your manuscript to us via either submit@scirp.org or Online Submission Portal.
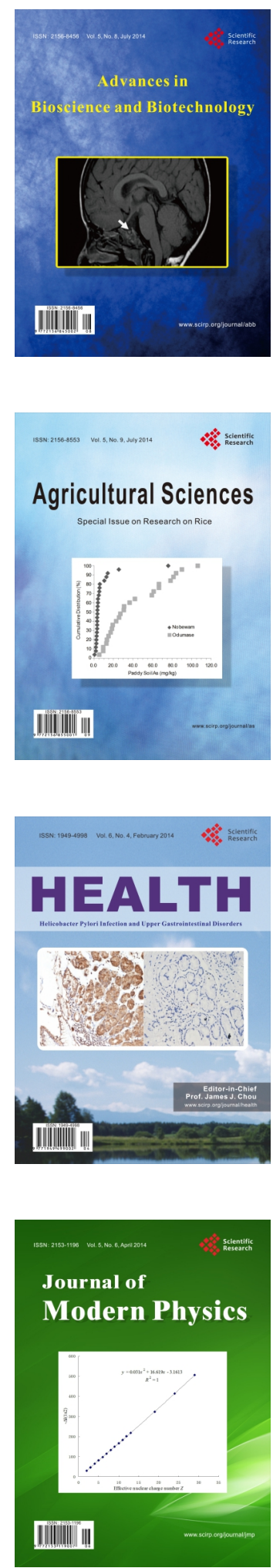
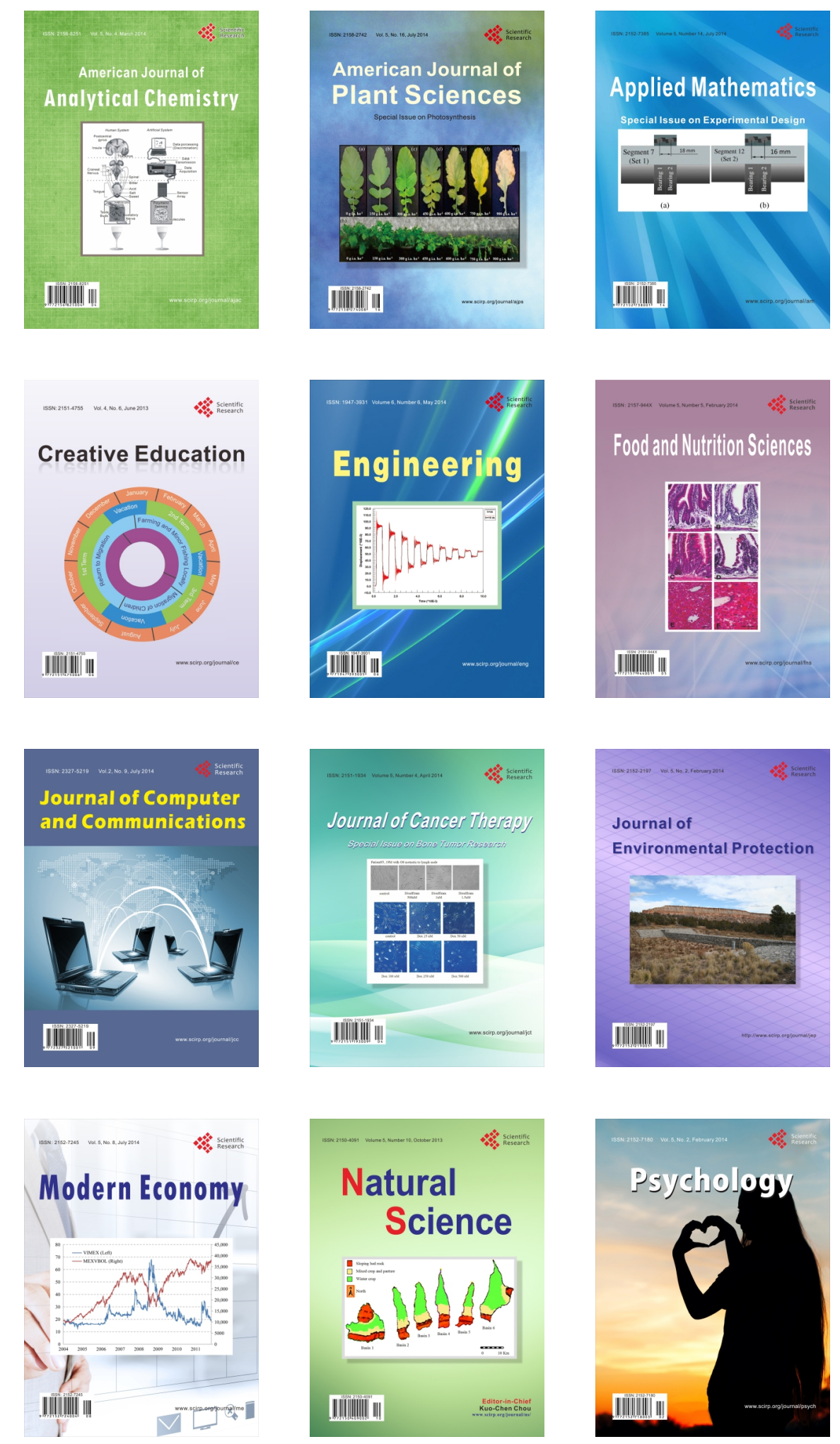